\title{
Technical aspects of endoscopic submucosal dissection (ESD). From lateral to longitudinal dissection: a new approach to treat colonic tumors
}

\author{
Gianmattia DEL GENIO, Francesco Saverio LUCIDO and Claudio GAMBARDELLA
}

Received: 17 May 2021

Accepted: 11 June 2021

\section{INTRODUCTION}

Treatment of colonic neoplasia has been driven towards a minimally invasive approach to reduce postoperative discomfort and co-morbidity ${ }^{(1,2)}$. In the last two decades, several randomized trials showed laparoscopic approach to reach similar or even superior results compared to standard open surgery ${ }^{(3,4)}$. Given the diffusion of accurate endoscopic screening for colonic neoplasia, a higher percentage of colonic tumors are currently discovered at an early stage, before further anatomical alterations become clinically evident (i.e., altered defecation and/or rectal bleeding) ${ }^{(5,6)}$. In the effort of reducing postoperative complications and discomfort, as well as achieving a faster return to normal activity preserving the physiologic colorectal function, endoscopic excision has been proposed to address colonic lesions at this early stage ${ }^{(7,8)}$. This natural orifice trans-luminal endoscopic surgery (NOTES) established in Japan gained soon widespread popularity due to excellent long-term survival associated to an extremely reduced invasiveness ${ }^{(9,10)}$. This is particularly evident for middle and low rectal lesions that classically required temporary ileostomy or abdomino-perineal excision in some cases. More recently, new criteria for endoscopic treatment of malignant lesions in the lower gastrointestinal tract (colon and rectum) have been well-defined (e.g., G1/G2, LO, invasion depth $\leq 1000 \mu \mathrm{m})$. The introduction of high definition flexible endoscopy and dedicated instruments specifically developed for performing more complex endoscopic resections, contributed to the increased interest of endoscopic community in underlying technical limitations and difficulties associated to the procedure ${ }^{(11)}$. Endoscopic submucosal dissection (ESD) is currently recognized as an effective treatment of larger $(>15 \mathrm{~mm})$ and poor lifting colonic lesions when en-bloc/R0 resection is required. Indeed, while standard endoscopic mucosal resection (EMR) is potentially associated with insufficient resection margin, ESD allows a correct judgment of either histological margin and stage. A recent metanalysis demonstrated that ESD rates of en-bloc curative resection were much higher but recurrence much lower $(91.7 \%, 80.3 \%$, and $0.9 \%$, respectively) than those of EMR $(46.7 \%, 42.3 \% \text {, and } 12.2 \% \text {, respectively })^{(12)}$. However, ESD is considered a complex procedure due to some limitations such as risk of perforation, significantly higher than that associated with EMR (5.7 vs 1.4 per cent) ${ }^{(12)}$. One reported drawback of ESD is the lack of adequate tissue traction to allow a precise and effective dissection along the right plane as performed during surgery ${ }^{(13)}$. Another limitation is lack of triangulation compared to standard laparoscopy, so that endoluminal techniques remain difficult to accomplish due to limited view and available movements. That is, ESD procedure seems to be limited to few referral centers with great expertise in interventional endoscopy ${ }^{(14)}$. Several ESD techniques have been described to overcome these drawbacks with variable outcomes and reported complications and to date, an extensive use of ESD to address large lesions could have been implemented with a more simplified, standardized and repeatable procedure $^{(15)}$. In fact, the reported length of ESD (range, 65-108 min) was about 3-fold longer when compared to standard EMR (range 29-30 min) (OR: 6.84; CI: 3.30-14.18)(13). More recently, different devices (e.g., similar to laparoscopic Johannes) seemed to better guarantee an easier approach to resect lesions under tension and to remove tissue with overall improved oncological outcome. In this setting, the lack of reports determines the real necessity of further technical standardization.

\section{TECHNICAL NOTE}

\section{Conventional flexible lateral dissection}

Traditional technique of ESD includes six steps to be completed sequentially: a) lesion identification and mucosal marking, b) submucosal injection, c) precutting (the very first small incision into the mucosa), d) complete cutting of the circumferential incision, e) submucosal dissection, f) hemostasis. The lesion marking and

Declared conflict of interest of all authors: none

Disclosure of funding: no funding received

University of Campania Luigi Vanvitelli, Division of General, Mininvasive and Bariatric Surgery, Naples, Italy.

Corresponding author: Claudio Gambardella. E-mail: claudiog86@hotmail.it 
the circumferential incision have been supported as a prudential approach reducing the incidence of uncompleted resection and perforation. This is related to the type of dissection; indeed, starting from the early introduction of needle-knife type devices (i.e., IT 1-2, Flex knives; Olympus America, Inc, Center Valley, Pa, USA. Hybrid knife; ERBE USA, Marietta, Ga. Mucosectome; Pentax, Tokyo, Japan) standard dissection is conducted by lateral movement of the endoscope with traction performed by the cap. This generates a simultaneous movement of dissection devices and the scope itself, along the surgical plane (FIGURE 1.A). A potential short-come of this technique may be represented by an intrinsic difficulty of maintaining a stable tissue traction as well as a steady clear image with an increased odd of achieving a wrong dissection line. This important limitation is more likely to occur when dealing with larger/occupying space lesion.

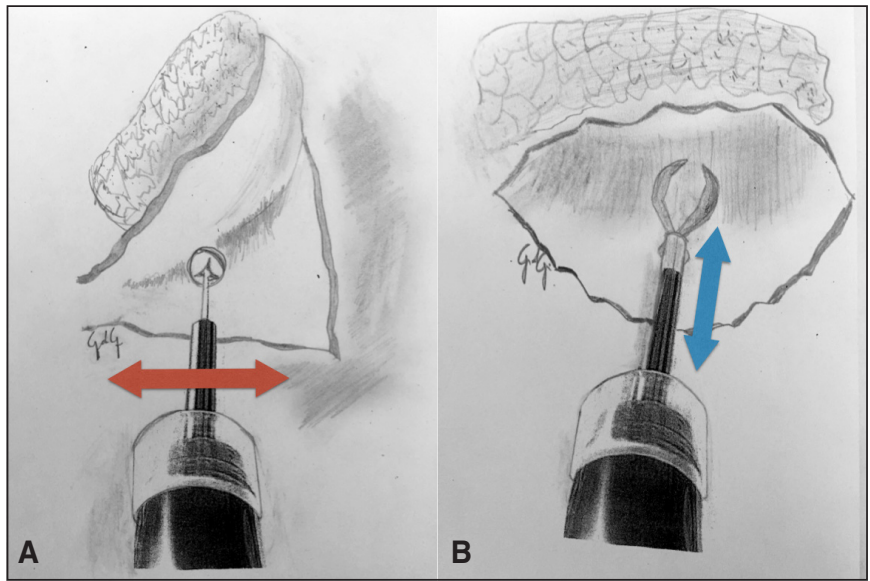

FIGURE 1. A) Endoscopic submucosal dissection performed by "flexible lateral dissection". Lateral movements of the endoscope tips allow to move the dissection and performing cut and suture. B) Endoscopic submucosal dissection accomplished by "fixed longitudinal dissection". The grasper grabs the tissue with subsequent energy delivery. The view remains stable being the scope maintained in a stationary position.

\section{Fixed longitudinal dissection}

To overcome the above mentioned issues, we proposed an alternative technique for dissection based on the experience gained with single incision laparoscopic surgery. In this view, the main technical issue during ESD is to avoid tissue collapse, providing constant traction and optimal view during resection. The employment of a double channel endoscope enables operators to perform the ESD procedure by simultaneously introducing two instruments into the lumen. This allows to keep either an adequate traction even when cup cannot lift the tissue up or to achieve good haemostasis by combined use of mono- and bipolar energy graspers. Care should be taken to cauterize all small vessels before cutting, since bleeding can obscure surgical field and increase operative time. In case of active unexpected bleeding, grasper should grab and close the vessel whilst suction is carried out to confirm bleeding stops, so that diathermy energy can be finally applied with an available optimal view. The most important advantage of this "grasper assisted" dissection, lays on the opportunity of working along the longitudinal axis of the instruments (FIGURE 1.B). This allows during a large portion of dissection, to move forward into the deeper resection plane along the sub-mucosal layer with no need of moving the endoscopic tip, thereby enabling a less complicated and technically demanding procedure. Another advantage of grabbing the tissue into the grasper claws is to modulate the delivery of energy with a higher rather than lower power setting depending on the amount of tissue to address. Specifically, when a vessel is supposed to be included into the branches a longer preventive electrocoagulation to be applied is recommended. Another potential advantage of this technique is endoscopist may apply the required energy power after lifting back the grasper, assessing tissue consistency, and controlling the right plane of dissection. This potentially reduce the risk of diffusion of energy at deeper layer, thus the risk of serosal perforation.

With this in mind, we may assume this "fixed" technique of dissection reproduce more than the flexible one the principles derived from minimally invasive surgery. That is, it seems to facilitate and utterly improve safety of ESD. However, although it would seem more feasible, this newly described approach to ESD needs caution and should be initially reserved to smaller resection in selected patients with well exposed lesion. It is always necessary to inform the patient, an immediate surgical procedure (transanal excision or laparoscopic resection/repair) may be necessary in case of perforation or a second stage surgery may be necessary to extend the resection, according to final pathology. We are confident on that future progress in devices technology will improve feasibility of ESD and further facilitate widespread practice of such promising technique, according to all the required principles of surgical oncology.

\section{Availability of data and materials}

The datasets used and/or analyzed during the current study are available from the Division of General, Mini-invasive and Obesity Surgery- Master of Coloproctology and Master of Pelvi-Perineal Rehabilitation. University of Study of Campania "Luigi Vanvitelli" Naples, on reasonable request.

\section{Authors' contribution}

Del Genio G, Lucido FS and Gambardella C: participated substantially in conception, design and execution of the study and in the analysis and interpretation of the data; also participated substantially in the drafting and editing of the manuscript. All authors contributed significantly to the present research, reviewed the entire manuscript and approved the final manuscript.

\section{Orcid}

Gianmattia Del Genio: 0000-0001-5603-8970.

Francesco Saverio Lucido: 0000-0002-8778-4690.

Claudio Gambardella: 0000-0003-2277-2960.

Del Genio G, Lucido FS, Gambardella C. Aspectos técnicos da dissecação submucosal endoscópica. Da dissecção lateral à longitudinal: uma nova abordagem para tratar tumores de cólon. Arq Gastroenterol. 2021;58(4):566-8.

Keywords - Endoscopic submucosal dissection; transanal excision; NOTES. 


\section{REFERENCES}

1. Esposito D, Maione F, D’Alessandro A, Sarnelli G, De Palma GD. Endoscopic treatment of esophageal achalasia. World J Gastrointest Endosc. 2016;8:30-9. doi: 10.4253/wjge.v8.i2.30

2. Del Genio G, Del Genio F, Schettino P, Limongelli P, Tolone S, Brusciano L, Avellino M, et al. Esophageal papilloma: Flexible endoscopic ablation by radiofrequency. World J Gastrointest Endosc. 2015;7:290-4. doi: 10.4253/wjge.v7.i3.290.

3. Veldkamp R, Kuhry E, Hop WC, Jeekel J, Kazemier G, Bonjer HJ, et al. Laparoscopic surgery versus open surgery for colon cancer: short-term outcomes of a randomised trial. Lancet Oncol. 2005;6:477-84. doi: 10.1016/S1470-2045(05)70221-7.

4. Yamamoto S, Inomata M, Katayama H, Mizusawa J, Etoh T, Konishi F, et al Short-term surgical outcomes from a randomized controlled trial to evaluate laparoscopic and open D3 dissection for stage II/III colon cancer: Japan Clinical Oncology Group Study JCOG 0404. Ann Surg. 2014;260:23-30. doi:10.1097। SLA.0000000000000499.

5. Corleto VD, Pagnini C, Cattaruzza MS, Zykaj E, Di Giulio E, Margagnoni G, et al. Is proliferative colonic disease presentation changing? World J Gastroenterol 2012;18:6614-9. doi: 10.3748/wjg.v18.i45.6614

6. Galuppini F, Pennelli G, Loupakis F, Lanza C, Vianello L, Sacchi D, et al. BRAF p.V600E-specific immunohistochemical assessment in colorectal cancer endoscopy biopsies is consistent with the mutational profiling. Histopathology. 2017;71:1008-11. doi: 10.1111/his.13315.

7. Brusciano L, Gambardella C, Del Genio G, Tolone S, Lucido FS, Terracciano $\mathrm{G}$, et al. Outlet obstructed constipation and fecal incontinence: is rehabilitation treatment the way? myth or reality. Arq Gastroenterol. 2020;5757:198. doi: 10.1590/s0004-2803.202000000-38

8. Gambardella C, Brusciano L, Del Genio G, Tolone S, Terracciano G, Gualtieri $\mathrm{G}$, et al. Predictive parameters to identify incontinent patients amenable for rehabilitation treatment: the muscular synergies evaluation. Arq Gastroenterol 2019;56:452-53. doi: 10.1590/S0004-2803.201900000-76.
9. Hirao M, Masuda K, Asanuma T, Naka H, Noda K, Matsuura K, et al. Endoscopic resection of early gastric cancer and other tumors with local injection of hypertonic saline-epinephrine. Gastrointest Endosc. 1988;34:264-9. doi: 10.1016/ s0016-5107(88)71327-9.

10. Hosokawa K, Yoshida S. Recent advances in endoscopic mucosal resection for early gastric cancer. Gan To Kagaku Ryoho. 1998;25:476-83.

11. Hsu WH, Sun MS, Lo HW, Tsai CY, Tsai YJ. Clinical practice of endoscopic submucosal dissection for early colorectal neoplasms by a colonoscopist with limited gastric experience. Gastroenterol Res Pract. 2013;2013:262171. doi $10.1155 / 2013 / 262171$.

12. Fujiya M, Tanaka K, Dokoshi T, Tominaga M, Ueno N, Inaba Y, et al. Efficacy and adverse events of EMR and endoscopic submucosal dissection for the treatment of colon neoplasms: a meta-analysis of studies comparing EMR and endoscopic submucosal dissection. Gastrointest Endosc. 2015;81:583-95. doi: 10.1016/j.gie.2014.07.034.

13. Kim GJ, Park SM, Kim JS, Ji JS, Kim BW, Choi H. Risk Factors for Additional Surgery after Iatrogenic Perforations due to Endoscopic Submucosal Dissection. Gastroenterol Res Pract. 2017;2017:6353456. doi: 10.1155/2017/6353456.

14. Yoshida N, Yagi N, Inada Y, Kugai M, Yanagisawa A, Naito Y. Prevention and management of complications of and training for colorectal endoscopic submucosal dissection. Gastroenterol Res Pract. 2013;2013:287173. doi: $10.1155 / 2013 / 287173$.

15. Draganov PV, Gotoda T, Chavalitdhamrong D, Wallace MB. Techniques of endoscopic submucosal dissection: application for the Western endoscopist? Gastrointest Endosc. 2013;78:677-88. doi: 10.1016/j.gie.2013.07.033. 